\title{
AMBIENTE FAMLIAR E CONDIÇÕES DE RISCO PARA O USO DE DROGAS EM ESTUDANTES UNIVERSITÁRIOS
}

\section{FAMILY ENVIRONMENT AND RISK CONDITIONS FOR DRUG USE AMONG COLLEGE STUDENTS}

Queiroz S, Rosenburg CP: Ambiente familiar e condições de risco para o uso de drogas em estudantes universitários. Rev Bras Cresc Desenv Hum 2004; 14(2): 11-20.

\begin{abstract}
Resumo: Objetivo. Identificar fatores de risco para uso de drogas relacionados ao ambiente familiar dos alunos de graduação dos 21 cursos da Universidade de São Paulo, na cidade de São Paulo. Métodos. Utilizando-se 11 variaveis obtidas através de um questionário anónimo e de auto-preenchimento, respondido por 2564 alunos sorteados, foi elaborado um modelo de regressão logística múltipla que agrupou fatores de risco para uso de droga, segundo as características do ambiente familiar do universitário. Para a variável dependente 'uso de droga', foram considerados o uso das seguintes drogas: maconha, alucinógenos, cocaina, crack, anfetaminas, anticolinérgicos, inalantes, tranqüilizantes, opiáceos, sedativos e anabolizantes. Resultados. O aluno usuário (comparado com o não-usuário) de nossa amostra é do sexo masculino (29,3\%), tem entre 20 e 24 anos (29,4\%), é solteiro (27,3\%), trabalha (28,7\%), mora com amigos (36,4\%) ou só $(34,9 \%)$, não tem $(33,4 \%)$ ou não pratica $(29,7 \%)$ uma religião, e não mantém um bom diálogo com seus pais, principalmente com a mãe (17,2\%). Obteve-se através do modelo multivariado um perfil de risco para uso de droga segundo as características do ambiente familiar,com 9 variaveis: escolaridade do pai e da mãe, renda familiar, mãe e irmão que fazem uso frequente de álcool, pais e irmãos com uso frequente de drogas e pais separados.
\end{abstract}

Palavras-chave: Uso de drogas. Estudantes universitários. Fatores de risco. Ambiente familiar.

O consumo de substâncias psicoativas vem gerando, nos quatro cantos do mundo, problemas sociais e de saúde. Olhando-se essa questão nos dias atuais, do ponto de vista social, percebe-se origens e ramificações de natureza política e econóômica ${ }^{1}$. Enquanto um problema de Saúde Pública, é importante a identificação precoce de seu uso e posterior abuso, o encaminhamento adequado dos usuários com quadros de dependência e, principalmente, a multiplicação de ações preventivas.

Para grande parte da sociedade brasileira, no entanto, encarar o uso de drogas como um problema de Saúde Pública ainda é uma idéia incipiente. A cada dia aumentam as evidências de que muitas das ações violentas e dos crimes bárbaros que vêm ocorrendo estejam associados ao uso e tráfico de drogas, mas a população ainda está mais sensibilizada para as medidas de segurança pública. Pede-se aumento do contingente policial, endurecimento das leis, mais cadeias, enquanto fica esquecida a necessidade urgente de políticas públicas claras e eficientes, relacionadas ao problema do abuso de drogas.

No mundo todo a repressão, no que se refere a álcool e drogas, tem apresentado tímidos resultados. Os Estados Unidos, país que investiu alto no combate ao narcotráfico de 1987 a 1991, reconheceram a ineficácia do método isolado e, em 1992, o congresso americano aprovou uma

\footnotetext{
* Psicóloga Clínica, Mestre e Doutora em Saúde Pública, Pesquisadora do GREA/HCFMUSP e do CDH. - Correspondência R:. Conde de Soussel,63 -S.Paulo - SP - 05436-130. e-mail: squeiroz@usp.br ** Professor Doutor do Departamento de Saúde Materno-Infantil da Faculdade de Saúde Pública da USP
} 
verba cuja maior parte era destinada à prevenção e não mais à repressão. A partir desse ano começou a ficar claro aos norte-americanos que, para que o problema do uso e do abuso de drogas diminuísse, seria necessário investir prioritariamente na prevenção. Compreenderam também a ineficácia de apenas combater os efeitos, através dos tratamentos, porque quando o problema da dependência já está instalado, a solução se torna bem mais complicada e onerosa.

Analisando-se a história das drogas, observa-se uma qualidade prazerosa inerente à droga, que poderia explicar, em grande parte, os primeiros usos. As pesquisas em prevenção se dedicam, então, à busca da compreensão de como superar esta condição prazerosa da droga. Muitas das medidas preventivas tentam evitar que o indivíduo se inicie no uso, porque quanto maior o prazer resultante deste uso, maior a chance do indivíduo continuar a fazêlo e maior o risco do desenvolvimento de uma dependência.

Entretanto, apesar de todos os esforços dirigidos à prevenção nos últimos 30 anos nos EUA, ainda não se tem uma idéia muito clara de como fazê-la. Conhecimentos importantes foram adquiridos, mas prevenção ao uso de drogas permanece um assunto controverso. Sabe-se, no entanto, que a pesquisa em prevenção está evoluindo e continuará a se desenvolver como conseqüência direta de um pensamento teórico e conceitual mais complexo, com medidas mais válidas e conotáveis dos problemas relacionados ao uso de drogas, melhor compreensão dos fatores de risco individuais, melhor identificação dos indivíduos e grupos de alto risco, o aprimoramento no delineamento de pesquisas, estudos longitudinais e melhor integração entre os vários segmentos - família, escola, comunidade, religião e justiça criminal ${ }^{2}$

Dentre os trabalhos de pesquisa na área de álcool e drogas existentes no Brasil, estudos epidemiológicos realizados com estudantes do primeiro e segundo graus, em dez capitais brasileiras e sete cidades do interior do estado de São Paulo $^{3}$, revelaram alta prevalência do uso na vida de substâncias psicoativas, indo de 17,8\% em Belém até 27,3\% em São Paulo. Dessas, as mais usadas foram os solventes $(15,4 \%)$, a maconha (5,5\%) e os ansiolíticos (5,0\%).

Outro levantamento ${ }^{4}$ mostrou uma prevalência maior para o uso de drogas entre estudantes universitários da cidade de São Paulo, que a dos estudantes de primeiro e segundo graus. Quanto às drogas mais usadas alguma vez na vida, à exceção de álcool e tabaco, aparecem: os inalantes
(28\%), a maconha (26\%), os medicamentos prescritos (17\%) e a cocaína (10\%).

Ainda com os universitários como público-alvo, pesquisa sobre o uso de substâncias psicoativas por estudantes de medicina da Universidade de São Paulo ${ }^{5}$, apresentou prevalências diversas, concordando, porém, com a ordem das drogas mais usadas na vida: solventes (23\%), maconha (19\%), e tranqüilizantes (11\%).

Embora estas e outras pesquisas na área sejam difíceis de comparar, por usarem diferentes metodologias, com amostras parciais, seus resultados indicam que, para a maioria dos estudantes, o uso de álcool e drogas é esporádico e experimental, o que reforça a necessidade de se investir em programas de prevenção dirigidos a estes alunos, buscando evitar que o uso esporádico se transforme em abuso e dependência, e preparando melhor os futuros profissionais para assumirem seus papéis enquanto agentes formadores de opinião pública.

$\mathrm{O}$ uso de drogas deve ser entendido como resultado da interação entre três fatores: droga, ambiente e indivíduo e a prevenção é a melhor estratégia para se intervir nesta interação ${ }^{6}$. Daí a importância do desenvolvimento da pesquisa sobre prevenção no Brasil, pois não se pode simplesmente importar resultados obtidos no estrangeiro e aplicá-los aqui. Podemos trazer modelos que servirão apenas como referências e nos ajudarão na caracterização de um determinado ambiente e do indivíduo inserido neste ambiente. Este trabalho é parte do primeiro estudo brasileiro sobre riscos para uso de drogas ${ }^{7}$.

Instituições e pesquisadores têm observado que a efetividade de programas de prevenção de drogas depende do conhecimento prévio das condições do ambiente (fatores de risco ambientais), e das características sociodemográficas, atitudes e padrão de uso de drogas da população em foco (fatores de risco do indivíduo), porque são estas as informações que deverão definir o tipo de intervenção a ser realizada ${ }^{8}$. O quadro de fatores de risco emergentes da literatura é vasto, principalmente pela multiplicidade e complexidade dos problemas associados ao uso de drogas. Assim como ocorre em relação à vulnerabilidade a uma doença qualquer, fatores de risco em diferentes combinações e em diferentes níveis podem resultar no uso de drogas.

Pode-se dizer que nenhum desses fatores de risco isoladamente é determinante do uso de drogas, mas quanto maior o número de fatores presentes, maior a chance de o indivíduo usar ou vir a usar drogas. Daí a importância do processo de identificação destes fatores para a constituição de um trabalho de prevenção. 


\section{MÉTODOS}

Trabalhou-se com uma amostra aleatória de estudantes de graduação da USP no ano de 1996 ( $\mathrm{n}=3539)$. Foi utilizado como instrumento do estudo um questionário anônimo e de autopreenchimento voluntário, nos moldes propostos pela Organização Mundial da Saúde ${ }^{9}$. Os dados obtidas foram analisados buscando-se um perfil dos alunos e os fatores do ambiente familiar associados ao uso de drogas.

Todas as perguntas feitas foram no sentido de levantar informações, atitudes e padrão de uso de drogas e não para avaliar o indivíduo quanto à existência ou não de um quadro de maior gravidade, como a dependência de drogas. Por se tratar de um levantamento sobre uso de drogas, a linguagem utilizada desempenhou papel preponderante para facilitar o acesso à população alvo, proporcionando a sua aproximação e participação napesquisa. Procurou-se, portanto, evitar títulos e palavras que pudessem gerar mal estar nas pessoas envolvidas.

Para a variável dependente, uso de droga, foi definido como droga a reunião de 11 substâncias: maconha, cocaína, crack, anfetaminas, alucinógenos, inalantes, anticolinérgicos, tranqüilizantes, opiáceos, sedativos e anabolizantes; e, como uso, qualquer referência de utilização das mesmas no último ano. Optou-se pela variável uso nos últimos 12 meses e não uso na vida, pelo fato de trabalharse com uma população de adultos jovens. Ficou definido como usuário de droga qualquer aluno que relatou ter feito uso de droga nos últimos 12 meses. Não foram incluídas apenas duas das drogas pesquisadas, o álcool e o tabaco, por terem elas um padrão de uso muito diferenciado: incluem-se na categoria drogas lícitas e têm seu uso social amplamente aceito em nossa cultura.

As variáveis independentes estão aqui agrupadas em 2 tópicos, descritos nos quadros 1 e 2: as variaveis que compõem um perfil do aluno e as referentes ao seu ambiente familiar. Foi realizado o cruzamento entre a variável dependente uso de droga e as 11 variaveis independentes, agrupadas sob o tópico Ambiente familiar.

Utilizou-se o teste de qui-quadrado de Pearson para avaliar a associação entre o uso de droga e cada variável independente.

Para o levantamento dos falares e/ou situac, ões do ambiente familiar que tenham maior probabilidade de predispor o aluno ao uso de substanciar psicoativas, foi elaborado um modelo de regressão logística múltipla, através da execução dos seguintes passas: 1. Foram construídos modelos univariados, com todas as ariaveis que mostraram associação (pc0,05) pelo teste de qui-quadrado 2 .
Quadro 1. Variáveis que compõem o perfil do aluno

\begin{tabular}{|c|c|}
\hline variável & categoria \\
\hline xo & $\begin{array}{l}\text { masculino } \\
\text { feminino }\end{array}$ \\
\hline faixa etária & $\begin{array}{l}15 \text { a } 19 \\
20 \text { a } 24 \\
25 \text { a } 29 \\
30 \text { ou }+\end{array}$ \\
\hline estado civil & $\begin{array}{c}\text { solteiro } \\
\text { casado } \\
\text { vive junto }\end{array}$ \\
\hline condições de moradia & $\begin{array}{c}\text { pais } \\
\text { cônjuge } \\
\text { amigos } \\
\text { sozinho } \\
\text { CRUSP } \\
\text { outros }\end{array}$ \\
\hline ter religião & $\begin{array}{l}\text { sim } \\
\text { não }\end{array}$ \\
\hline praticar religião & $\begin{array}{l}\text { sim } \\
\text { não }\end{array}$ \\
\hline atividade remunerada & $\begin{array}{l}\text { sim } \\
\text { não }\end{array}$ \\
\hline principal confidente & $\begin{array}{c}\text { mãe } \\
\text { pai } \\
\text { irmão } \\
\text { amigos } \\
\text { namorado(a) } \\
\text { terapeuta } \\
\text { ninguém } \\
\text { outros }\end{array}$ \\
\hline
\end{tabular}

Obtidos os modelos univariados, apenas aquelas variaveis que mostraram alguma associação (pc < 0,05) passaram para a etapa seguinte de regressão logísticamúltipla, com procedimento de seleção “stepwise forward”. Considerou-se fatores que predispõe ao risco, as categorias com odds ratio (OR) maiores que 1,0. Foram escolhidas como categorias de referência (baseline), aquelas com o menor índice de uso de droga.

\section{RESULTADOS}

A casuística deste estudo compreendeu um total de 2506 alunos. Vê-se na tabela 1 que a maioria dos alunos era solteira $(91,4 \%)$, morava com os pais (74,1\%) e tinha idade entre 15 e 24 anos (80,7\%), com a maior proporção entre os 20 e 24 anos (60\%). Quanto ao gênero, tivemos uma distribuição de 57,2\% para o sexo masculino e de $42,8 \%$ para o sexo feminino. Dos alunos pesquisados, um pouco mais da metade $(57,5 \%)$ relatou 
Quadro 2. Variáveis relacionadas ao ambiente familiar do aluno

\begin{tabular}{|c|c|}
\hline variável & categoria \\
\hline escolaridade do pai & $\begin{array}{c}\text { nenhuma educação formal } \\
1^{\circ} \text { grau incompleto } \\
1^{\circ} \text { grau completo } \\
2^{\circ} \text { grau incompleto } \\
2^{\circ} \text { grau completo } \\
\text { superior incompleto } \\
\text { superior completo } \\
\text { não sabe }\end{array}$ \\
\hline escolaridade da mãe & $\begin{array}{c}\text { nenhuma educação formal } \\
1^{\circ} \text { grau incompleto } \\
1^{\circ} \text { grau completo } \\
2^{\circ} \text { grau incompleto } \\
2^{\circ} \text { grau completo } \\
\text { superior incompleto } \\
\text { superior completo } \\
\text { não sabe }\end{array}$ \\
\hline renda familiar & $\begin{array}{l}\text { até } 10 \text { sm (salário mínimo) } \\
\text { de } 11 \text { a } 20 \mathrm{sm} \\
\text { de } 21 \text { a } 30 \mathrm{sm} \\
\text { de } 31 \text { a } 40 \mathrm{sm} \\
+ \text { de } 40 \mathrm{sm}\end{array}$ \\
\hline pais vivem & $\begin{array}{c}\text { juntos } \\
\text { separados } \\
\text { pais ou mãe falecidos }\end{array}$ \\
\hline $\begin{array}{l}\text { problemas causados pela } \\
\text { bebida por algum familiar }\end{array}$ & $\begin{array}{l}\text { sim } \\
\text { não }\end{array}$ \\
\hline $\begin{array}{l}\text { pai faz uso freqüente de } \\
\text { álcool }\end{array}$ & $\begin{array}{l}\text { sim } \\
\text { não }\end{array}$ \\
\hline $\begin{array}{c}\text { mãe faz uso freqüente de } \\
\text { álcool }\end{array}$ & $\begin{array}{l}\text { sim } \\
\text { não }\end{array}$ \\
\hline $\begin{array}{c}\text { irmão faz uso freqüente } \\
\text { de álcool } \\
\end{array}$ & $\begin{array}{l}\text { sim } \\
\text { não }\end{array}$ \\
\hline $\begin{array}{c}\text { pai faz uso freqüente de } \\
\text { drogas }\end{array}$ & $\begin{array}{l}\text { sim } \\
\text { näo }\end{array}$ \\
\hline $\begin{array}{l}\text { mãe faz uso freqüente de } \\
\text { drogas }\end{array}$ & $\begin{array}{l}\text { sim } \\
\text { não }\end{array}$ \\
\hline $\begin{array}{c}\text { irmāo faz uso freqüente } \\
\text { de drogas }\end{array}$ & $\begin{array}{l}\text { sim } \\
\text { não }\end{array}$ \\
\hline
\end{tabular}

ter trabalhado no semestre anterior à coleta de dados. Observaram-se associações estatisticamente significativas, com p menor ou igual a 0,01 , quando compararam-se os grupos dos que usam droga, com o dos que não usam droga em relação às variáveis: sexo, faixa etária, estado civil, condições de moradia, ter religião, praticar religião, exercer atividade remunerada e principal confidente.

Na tabela 2, onde encontramos as variáveis referentes ao ambiente familiar do aluno, vemos que, de todas as variáveis apenas uma delas - "algum membro da família bebeu a ponto de causar problemas em casa, no trabalho ou com amigos" - não mostrou diferença entre os grupos de usuários e não-usuários. Para as outras encontramos uma forte associação com o uso de droga,
Nas variaveis 'escolaridade do pai' e 'escolaridade da mãe', temos que a proporção de uso de droga cresce com o aumento do grau de escolaridade. O mesmo se observa em relação à renda familiar: quanto maior a renda, maior a porcentagem de alunos que usam. É interessante observar que $60,1 \%$ dos pais e $44,7 \%$ das mães dos universitários da USP possuem grau de escolaridade superior, ainda que incompleto.

O índice de uso é maior para os alunos cujos pais vivem separados (35,5\%), que aqueles cujos pais vivem juntos (26,2\%) ou já são falecidos (20,5\%). Quanto ao uso freqüente de álcool ou de outras drogas pelos familiares, encontramos uma diferença significativa qualquer que seja a pessoa da família ou a droga utilizada.

Para o modelo multivariado final das características do ambiente familiar dos alunos da USP relacionadas ao uso de droga, temos 9 variáveis de risco, conforme mostra a tabela 3 . A escolaridade dos pais aparece como um fator que influencia o uso de droga. Filhos de pais com grau superior de instrução tem 1,7 vezes mais chances de usar droga; mesmo que o nível de instrução do pai seja o segundo grau, já existe um risco maiorde 1,5 vezes - quando comparado com o pai que, no máximo, terminou o primeiro grau. Quando a mãe tem nível superior, o risco de uso de droga é de 1,6 vezes maior que o daqueles cujas mães só estudaram até o primeiro grau.

Filhos de famílias com rendas mensais maiores que 40 salários mínimos têm 1,4 mais chance de usar droga que aqueles vindos de uma família de menor poder aquisitivo, com rendas de até 20 salários mínimos.

Filhos de mães que fazem uso freqüente de álcool estão 2,1 vezes mais em risco de usar droga, do que aqueles cujas mães não usam freqüentemente. $\mathrm{O}$ mesmo acontece para os que têm irmãos com uso freqüente de álcool, com um risco 1,5 vez maior do que os alunos cujos irmãos não fazem uso freqüente de álcool.

Os maiores fatores de risco aparecem relacionados a familiares com uso freqüente de drogas. Estudantes que tenham pai que faça uso freqüente de drogas têm 2,5 vezes mais chance de usar drogas do que os que têm pai que não use com freqüência. Se o uso freqüente de drogas é feito pela mãe, o risco é 1,7 vezes maior do que para os universitários cujas mães não façam esse uso. Já o estudante que tenha algum irmão que faça uso freqüente de droga tem o seu risco de usar elevado para 3,3, quando comparado com os que não têm irmãos que façam uso freqïente.

Outro fator de risco independente para o uso de droga é a situa,cão marital dos pais. Filhos de pais separados têm 1,5 vez mais 
chances de usar droga, quando comparado com os que têm pelo menos um dos pais já falecidos. Em contrapartida, filhos de pais que mo- rem juntos não apresentaram risco significante se comparados com aqueles cujos pais já são falecidos.

Tabela 1 - Número e porcentagem de estudantes Iniversitários da USP no ano de 1996 segundo o uso de drogsas e características pessoais

\begin{tabular}{|c|c|c|c|c|c|c|c|c|}
\hline \multirow[t]{2}{*}{ Variável } & \multirow[t]{2}{*}{ Categoria } & \multicolumn{2}{|c|}{ Usa } & \multicolumn{2}{|c|}{ Não Usa } & \multicolumn{2}{|c|}{ Total } & \multirow[t]{2}{*}{$\mathrm{p}^{*}$} \\
\hline & & n & $\%$ & n & $\%$ & n & $\%$ & \\
\hline \multirow[t]{2}{*}{ Sexo } & Masculino & 417 & 29,3 & 1006 & 70,7 & 1423 & 57,2 & \\
\hline & Feminino & 244 & 229 & 821 & 77,1 & 1065 & 42,8 & \\
\hline Total & & 661 & 26,6 & 1827 & 73,4 & 2488 & 100,0 & 0,0003 \\
\hline \multirow[t]{4}{*}{ Faixa Etária } & $15-19$ & 123 & 24,0 & 389 & 76,0 & 512 & 20,6 & \\
\hline & $20-24$ & 440 & 29,4 & 1057 & 70,6 & 1497 & 60,1 & \\
\hline & $25-29$ & 73 & 22,5 & 252 & 77,5 & 325 & 13,1 & \\
\hline & $30 \mathrm{ou}+$ & 26 & 16,7 & 130 & 83,3 & 156 & 6,3 & \\
\hline Total & & 662 & 26,6 & 1828 & 73,4 & 2490 & 100,0 & 0,0003 \\
\hline \multirow[t]{3}{*}{ Estado Civil } & Solteiro & 622 & 27,3 & 1655 & 72,7 & 2277 & 91,4 & \\
\hline & Casado/juntado & 33 & 17,2 & 159 & 82,8 & 192 & 7,7 & \\
\hline & Outro & 07 & 33,3 & 14 & 66,7 & 21 & 0,8 & \\
\hline Total & & 662 & 26,6 & 1828 & 73,4 & 2490 & 100,0 & 0,0074 \\
\hline \multirow[t]{6}{*}{ Moradia } & Pais & 473 & 25,7 & 1368 & 74,3 & 1841 & 74,1 & \\
\hline & Cônjuge & 33 & 17,8 & 152 & 82,2 & 185 & 7,4 & \\
\hline & Amigos & 91 & 36,5 & 158 & 63,5 & 249 & 10,0 & \\
\hline & Sozinho & 44 & 34,9 & 82 & 65,1 & 126 & 5,1 & \\
\hline & CRUSP $^{+}$ & 16 & 24,6 & 49 & 75,4 & 65 & 2,6 & \\
\hline & Outros & 04 & 20,0 & 16 & 80,0 & 20 & 0,8 & \\
\hline Total & & 661 & 26,6 & 1825 & 73,4 & 2486 & 100,0 & 0,0001 \\
\hline \multirow[t]{2}{*}{ Ter religião } & Sim & 435 & 24,0 & 1379 & 76,0 & 1814 & 73,2 & \\
\hline & Não & 222 & 33,4 & 442 & 66,6 & 664 & 26,8 & \\
\hline Total & & 657 & 26,5 & 1821 & 73,5 & 2478 & 100,0 & $<0,0001$ \\
\hline Praticar & Sim & 158 & 19,3 & 661 & 80,7 & 819 & 34,8 & \\
\hline Religião & Não & 455 & 29,7 & 1079 & 70,3 & 1534 & 65,2 & \\
\hline Total & & 613 & 26,1 & 1740 & 73,9 & 2353 & 100,0 & $<0,0001$ \\
\hline Atividade & Sim & 410 & 28,7 & 1021 & 71,3 & 1431 & 57,5 & \\
\hline Remunerada & Não & 252 & 23,8 & 806 & 76,2 & 1058 & 42,5 & \\
\hline Total & & 662 & 26,6 & 1827 & 73,4 & 2489 & 100,0 & 0,0070 \\
\hline Principal & Măe & 109 & 17,2 & 525 & 82,8 & 634 & 27,0 & \\
\hline \multirow[t]{7}{*}{ Confidente } & Pai & 38 & 24,1 & 120 & 75,9 & 158 & 6,7 & \\
\hline & Irmão & 48 & 31,2 & 106 & 68,8 & 154 & 6,6 & \\
\hline & Amigos & 201 & 39,7 & 305 & 60,3 & 506 & 21,6 & \\
\hline & Namorado(a) & 122 & 24,2 & 382 & 75,8 & 504 & 21,5 & \\
\hline & Terapeuta & 18 & 42,9 & 24 & 57,1 & 42 & 1,8 & \\
\hline & Ninguém & 81 & 25,2 & 240 & 74,8 & 321 & 13.7 & \\
\hline & Outros & 02 & 8,0 & 23 & 92,0 & 25 & 1,1 & \\
\hline Total & & 619 & 26,4 & 1725 & 73,6 & 2344 & 100,0 & $<0,0001$ \\
\hline
\end{tabular}

p*: livel descritivo do teste de associaçãode Pearson. Na realização do teste foi excl Ida a categoria 'ignorado'. +: CRUSP 
Tabela 2 - Número e porcentagem de estudantes universitários da USP no ano de 1996 segundo o uso de droga e Características do ambiente familiar.

\begin{tabular}{|c|c|c|c|c|c|c|c|c|}
\hline \multirow[t]{2}{*}{ Variável } & \multirow[t]{2}{*}{ Categoria } & \multicolumn{2}{|c|}{ Usa } & \multicolumn{2}{|c|}{ Não Usa } & \multicolumn{2}{|c|}{ Total } & \multirow[t]{2}{*}{$\mathrm{p}^{*}$} \\
\hline & & $\mathbf{n}$ & $\%$ & $\mathbf{n}$ & $\%$ & $\mathbf{n}$ & $\%$ & \\
\hline \multirow{9}{*}{ Escolaridade do pai } & Sem educação formal & 02 & 7,4 & 25 & 92,6 & 27 & 1,1 & \\
\hline & $1^{\circ}$ grau incompleto & 34 & 13,1 & 226 & 86,9 & 260 & 10,5 & \\
\hline & $1^{\circ}$ grau & 32 & 15,2 & 179 & 84,8 & 211 & 8,5 & \\
\hline & $2^{\circ}$ grau incompleto & 22 & 18,6 & 96 & 81,4 & 118 & 4,8 & \\
\hline & $2^{\circ}$ grau & 83 & 23,5 & 270 & 76,5 & 353 & 14,2 & \\
\hline & Superior incompleto & 43 & 29,9 & 101 & 70,1 & 144 & 5,8 & \\
\hline & Superior & 435 & 32,3 & 911 & 67,7 & 1346 & 54,3 & \\
\hline & Nã̃o sabe & 10 & 52,6 & 09 & 47,4 & 19 & 0,8 & \\
\hline & Total & 661 & 26,7 & 1817 & 73,3 & 2478 & 100,0 & $<0,0001$ \\
\hline \multirow[t]{9}{*}{ Escolaridade da mãe } & Sem educação formal & 03 & 13,6 & 19 & 86,4 & 22 & 0,9 & \\
\hline & $1^{\circ}$ grau incompleto & 48 & 15,4 & 264 & 84,6 & 312 & 12,6 & \\
\hline & $1^{\circ}$ grau & 54 & 16,9 & 265 & 83,1 & 319 & 12,8 & \\
\hline & $2^{\circ}$ grau incompleto & 31 & 21,2 & 115 & 78,8 & 146 & 5,9 & \\
\hline & $2^{\circ}$ grau & 146 & 26,2 & 412 & 73,8 & 558 & 22,5 & \\
\hline & Superior incompleto & 57 & 34,8 & 107 & 65,2 & 164 & 6,6 & \\
\hline & Superior & 319 & 33,7 & 628 & 66,3 & 947 & 38,1 & \\
\hline & Não sabe & 04 & 26,7 & 11 & 73,3 & 15 & 0,6 & \\
\hline & Total & 662 & 26,7 & 1821 & 73,3 & 2483 & 100,0 & $<0,0001$ \\
\hline \multirow[t]{6}{*}{ Renda Familiar } & Até $10 \mathrm{SM}^{+}$ & 65 & 18,6 & 284 & 81,4 & 349 & 14,8 & \\
\hline & De 11 a 20 SM & 125 & 21,9 & 445 & 78,1 & 570 & 24,2 & \\
\hline & De 21 a 30 SM & 123 & 26,3 & 344 & 73,7 & 467 & 19,8 & \\
\hline & De31 a 40 SM & 104 & 28,1 & 266 & 71,9 & 370 & 15,7 & \\
\hline & $+\mathrm{de} 40 \mathrm{SM}$ & 212 & 35,1 & 392 & 64,0 & 604 & 25,6 & \\
\hline & Total & 629 & 26,7 & 1731 & 73,3 & 2360 & 100.0 & $<0.0001$ \\
\hline \multirow{4}{*}{ Pais vivem } & Juntos & 503 & 26,2 & 1420 & 73,8 & 1923 & 77,4 & \\
\hline & Separados & 108 & 35,5 & 196 & 64,5 & 304 & 12,2 & \\
\hline & Falecido(s) & 53 & 20,5 & 205 & 79,5 & 258 & 10,4 & \\
\hline & Total & 664 & 26,7 & 1822 & 73,3 & 2486 & 100,0 & 0,0005 \\
\hline \multirow{3}{*}{$\begin{array}{l}\text { Familiar causou prob. } \\
\text { pela bebida }\end{array}$} & Sim & 94 & 29,3 & 227 & 70,7 & 321 & 13,8 & \\
\hline & Não & 547 & 27,4 & 1450 & 72,6 & 1997 & 86,2 & \\
\hline & Total & 641 & 27,7 & 1677 & 72,3 & 2318 & 100,0 & 0,4817 \\
\hline \multirow{3}{*}{$\begin{array}{l}\text { Pai/uso frequiente de } \\
\text { álcool** }\end{array}$} & Sim & 150 & 32,4 & 313 & 67,6 & 463 & 19,7 & \\
\hline & Não & 499 & 26,4 & 1388 & 73,6 & 1887 & 80,3 & \\
\hline & Total & 649 & 27,6 & 1701 & 72,4 & 2350 & 100,0 & 0,0102 \\
\hline \multirow{3}{*}{$\begin{array}{l}\text { Mãe/uso frequiente de } \\
\text { álcool** }\end{array}$} & Sim & 48 & 52,7 & 43 & 47,3 & 91 & 3,9 & \\
\hline & Não & 601 & 26,6 & 1658 & 73,4 & 2259 & 96,1 & \\
\hline & Total & 649 & 27,6 & 1701 & 72,4 & 2350 & 100,0 & $<0,0001$ \\
\hline \multirow{3}{*}{$\begin{array}{l}\text { Immão/uso freqüente de } \\
\text { alcool** }\end{array}$} & Sim & 109 & 41,1 & 156 & 58,9 & 265 & 11,3 & \\
\hline & Não & 540 & 25,9 & 1545 & 74,1 & 2085 & 88,7 & \\
\hline & Total & 649 & 27,6 & 1701 & 72,4 & 2350 & 100,0 & $<0,0001$ \\
\hline \multirow{3}{*}{$\begin{array}{l}\text { Pai/uso freqüente de } \\
\text { drogas**** }\end{array}$} & Sim & 22 & 57,9 & 16 & 42,1 & 38 & 1,5 & \\
\hline & Não & 645 & 26,1 & 1823 & 73,9 & 2468 & 98,5 & \\
\hline & Total & 667 & 26,6 & 1839 & 73,4 & 2506 & 100,0 & $<0,0001$ \\
\hline \multirow{3}{*}{$\begin{array}{l}\text { Mãe/uso frequiente de } \\
\text { drogas*** }\end{array}$} & Sim & 43 & 47,8 & 47 & 52,2 & 90 & 3,6 & \\
\hline & Não & 624 & 25,8 & 1792 & 74,2 & 2416 & 96,4 & \\
\hline & Total & 667 & 26,6 & 1839 & 73,4 & 2506 & 100,0 & $<0,0001$ \\
\hline \multirow{3}{*}{$\begin{array}{l}\text { Irmão/uso frequiente de } \\
\text { drogas*** }\end{array}$} & Sim & 92 & 60,9 & 59 & 39,1 & 151 & 6,0 & \\
\hline & Não & 575 & 24,4 & 1780 & 75,6 & 2355 & 94,0 & \\
\hline & Total & 667 & 26,6 & 1839 & 73,4 & 2506 & 100,0 & $<0,0001$ \\
\hline
\end{tabular}

p*: nível descritivo do teste de associação de Pearson. Na realização do teste foi excluída a categoria ignorado. Uso freqûente de álcool**: no mínimo 3 vezes por semana o equivalente a 5 chopps ou 5 doses de whisly. Usp freqiiente de drogas***: no mínimo urna vez por sernana. 
Tabela 3 - Modelo multivariado final das variaveis de risco associadas ao uso de droga para características do ambiente familiar dos alunos da USP no ano de 1996

\begin{tabular}{llccc}
\hline \multicolumn{1}{c}{ Variável } & \multicolumn{1}{c}{ Categoria } & OR $^{++}$ & IC $_{95 \%}$ & P \\
\hline Escolaridade do pai & Superior & 1,7 & {$[1,2 ; 2,4]$} & 0,0011 \\
& $2^{\circ}$ grau & 1,5 & {$[1,0 ; 2,1]$} & 0,0417 \\
& $1^{\circ}$ grau & 1,0 & - & - \\
\hline Escolaridade da mãe & Superior & 1,6 & {$[1,2 ; 2,1]$} & 0,0033 \\
& $1^{\circ}$ grau & 1,0 & - & - \\
\hline Renda familiar & +40 sm+ & 1,4 & {$[1,0 ; 1,8]$} & 0,0124 \\
& até 20 sm & 1,0 & - & - \\
\hline Mãe faz uso freqüente de álcool & Sim & 2,1 & {$[1,3 ; 3,4]$} & 0,0011 \\
& Não & 1,0 & - & - \\
\hline Irmão faz uso freqüente de álcool & Sim & 1,5 & {$[1,1 ; 2,1]$} & 0,0054 \\
& Não & 1,0 & - & - \\
\hline Pai faz uso freqüente de droga & Sim & 2,5 & {$[1,2 ; 5,3]$} & 0,0113 \\
& Não & 1,0 & - & - \\
\hline Mãe faz uso freqüente de droga & Sim & 1,7 & {$[1,1 ; 2,8]$} & 0,0222 \\
& Não & 1,0 & - & - \\
\hline Irmão faz uso freqüente de droga & Sim & 3,3 & {$[2,3 ; 4,7]$} & $<0,0001$ \\
& Não & 1,0 & - & - \\
\hline Pais & Separados & 1,5 & {$[1,0 ; 2,3]$} & 0,0369 \\
& Pai ou mãe falecidos & 1,0 & - & - \\
\hline
\end{tabular}

+ sm = salário mínimo.

$++\mathrm{OR}=$ odds ratio.

\section{DISCUSSÃO}

Dentro daquilo que considera-se, neste estudo, características relacionadas ao ambiente familiar, foi obtido um perfil de risco com os estudantes provenientes de famílias mais abastadas, cujos pais tenham maior nível de escolaridade e sejam separados. Além disso, vê-se um risco aumentado quando membros da família fazem uso freqüente de álcool ou drogas, com exceção para uso freqüente de álcool pelo pai.

A literatura é quase unânime quanto ao aumento do risco de uso de drogas em famílias com história de uso e abuso de álcool e drogas ${ }^{10-14}$.

Apesar de tantas evidências, um estudo retrospectivo com adolescentes mexicanos de áreas urbanas ${ }^{15}$ encontrou, assim como neste trabalho, que o consumo de álcool pelo pai não teve associação positiva com o consumo de drogas do adolescente. Devido à alta porcentagem de alunos cujo pai faz uso freqüente de álcool - quase $20 \%$ - na população deste estudo, e as decorrentes implica- ções preventivas, sugerimos futura investigação sobre esta associação.

Deve-se salientar a importância da relação dos pais com o filho desde, e principalmente, os primeiros anos de vida, como um ponto central para a compreensão do desenvolvimento posterior do adultos. Estudos e teorias psicanalíticas ${ }^{17}$ mostram que as consequiências da carência paterna são tão graves quanto as da carência materna. Considerase, portanto, que o uso freqüente de álcool e drogas por familiares necessariamente influenciará na qualidade do relacionamento e dos vínculos estabelecidos entre os membros da família

Na literatura, além das já descritas, muitas outras variáveis foram testadas para explicar o relacionamento entre o uso de álcool e drogas pelos pais e irmãos e o aumento de vulnerabilidade do indivíduo. Estudou investigando os fatores associados ao uso de drogas em filhos de alcoolistas e não-filhos de alcoolistas, encontrou que a dificuldade para exercer a vigilância patema (saber onde o filho está e com quem) influenciava no uso de 
droga de seus filhos, para ambos os grupos. Resultado semelhante ao achado em outro trabalhou, que encontrou na vigilancia dos pais, um fator para proteção contra o uso de drogas dos filhos. Resultados que confrontados com os deste trabalho, instigam a seguinte questão investigativa: teriam os filhos de fanulias mais abastadas e de melhores níveis de instrução pais mais brandos e frouxos quanto ao controle de seus filhos ${ }^{7}$.

Estudo sobre jovens de alto-risco ${ }^{20}$, mostrou que dentre os fatores de risco associados à faneca estão: alcoolismo na família; pais que não conseguem estabelecer limites, valores e normas claras de comportamento e que dão punições excessivamente severas ou inconsistentes; e pais que usam drogas, ou que são tolerantes com o uso de drogas de seus filhos. Estudo brasileiro com estudantes universitários de Minas Gerais ${ }^{21}$, encontrou uma correlação entre o uso de drogas e a qualidade do relacionamento entre os pais, e observou ainda, que o relacionamento com a mãe é mais importante na associação com o uso de drogas, que o relacionamento com o pai. Estudo nacional ${ }^{23}$, realizado na Colômbia em 1993, encontrou dentre os fatores de risco para consumo de cocaína a má comunicação familiar, o consumo de droga pela família, o abuso de álcool na família, o recebimento de castigos injustos, e o irmão consumidor de drogas. Estudo ${ }^{23}$ importante de 1984 encontrou o uso de drogas pela mãe como sendo um dos fatores de risco para a progressão de uso de drogas de prescrição nas mulheres. A literatura mostra que irmãos mais velhos podem exercer tanto uma influência inibitória quanto uma encorajadora em seus irmãos mais novos, no que se refere ao uso de drogas.

Quaisquer que sejam os aspectos familiares que influenciam no uso de drogas, devemos lembrar a vulnerabilidade herdada geneticamente, mostrada através de estudos com irmãos, meio irmãos, irmãos gêmeos e crianças.
Este estudo encontrou um risco aumentado para uso de drogas em alunos cujos pais são separados, quando comparados a alunos que têm pelo menos um dos pais já falecidos. Dados corroborados por outro estudo ${ }^{25}$, que encontrou maior uso de droga entre familiares, nas famílias em que o jovem vive sozinho com um dos pais, ou junto com padrasto ou madrasta. Já em outro estudo não se observou grande importância para este fator, quando comparado com fatores relacionados ao estilo de vida e de experiência. Considera-se importante que novas pesquisas ponham ênfase no aspecto funcional/disfuncional da família, que pode estar servindo como um fator de confusão para os resultados do casal viver junto ou separado.

Assim como em outro estudo ${ }^{27}$, considera-se a escolaridade dos pais como uma boa medida para o nível sócio-econômico da família, o que vem reforçar a associação positiva encontrada entre risco de uso e famílias de classes sociais mais elevadas. Encontramos na literatura algumas evidências ${ }^{26-28} \mathrm{de}$ que o risco para o uso de drogas aumenta em filhos de pais mais educados ou com rendimentos mais atos. A literatura, no entanto, não é muito farta sobre esta relação, que, nos Estados Unidos, poderia ser explicada pela ênfase dada às variáveis raça e diferenças regionais, do que à variável classe social. Além do mais, comparações podem ser perigosas se pensarmos na enorme diferença entre a distribuição de renda no Brasil e nos países desenvolvidos. Uma possível explicação adaptada para nossa realidade de país, de cidade e tempo - é a de que a população estudada, composta por universitários da USP, tida como um dos vestibulares mais concorridos e difíceis do país, provenha de escolas de bom nível, o que atualmente se traduz por escolas particulares e caras. Deduz-se, então, que alunos provenientes de classes sociais mais baixas e com pais de menor escolaridade formal, precisariam ter atributos como dedicação, esforço, perseverança e responsabilidade, além de terem sido sempre bons alunos, para conseguirem furar este privilégio. Estudantes com estes atributos possivelmente se encaixaram melhor no gnpo de não-usuários de drogas.

\begin{abstract}
Objective. To indentify family environment risk factors for drug use in undergraduate students from 21 courses at the University of São Paulo (USP), in the city of São Paulo, Brazil. Methods. A multiple logistic regression model was constructed using data from 11 variables, in an anonymous, self-administered questionnaire, which was answered by 2,564 randomly sampled students. For the dependent variable 'drug use', the following drugs were considered: marijuana, hallucinogens, cocaine, crack, amphetamines, anticholinergics, inhalants, tranquilizers, anxiolytics, antidystonics, opiates, sedatives, barbiturates, and anabolizers. Results. In the sample, the user (compared with the non-user) is male (29.3\%), 20-24 years old (29.4\%), single (27.3\%), work (28.7\%), lives alone (34.9\%) or with friends (36.4\%), do not have a religion (33.4\%), or at least do not practicise it (29.7\%), have some difficulty communicating with his parents, particulariy with his mother (17.2\%).This resuited in a model that revealed a drug use risk profiie according to the characteristics of famiiy environment, in which 9 factors remained: famiiy income, parents levei of instruction, frequent use of alcohol by mother and brothers, frequent use of drugs by both parents and brothers.
\end{abstract}

Key Words: Drug use. University students. Risk factors. Family environment. 


\section{REFERÊNCIAS}

1 Lins e Silva T. Produção e consumo de drogas no contexto sócio-político contemporaneo. In: Bastos FI e Gonçalves O, organizadores. Só socialmente: os fatores psicoativos nas relações humanas através dos tempos. Rio de Janeiro: Relume-Dumará; 1992. p.51-56.

2 Leukefeld CG, Bukoski WJ, editors. An introduction to drug abuse prevention intervention research: methodological issues. Rockville:NIDA; 1991.p.1-ó.

3 Galduróz JCF, D’Almeida V, Carvalho V, Carlini EA. III Levantamento sobre o uso de drogas entre estudantes de lo. e 2O. graus em 10 capitais brasileiras - 1993. São Paulo: CEBRID/Depto. de Psicobiologia/ Escola Paulista de Medicina; 1994.

4 Magalhães MP, Barros RS, Silva MTA. Uso de drogas entre universitários: a experiência com maconha como fator delimitante. Ver ABP-APAL 1991; 13 (3): 97-104.

5. Mesquita AMC, Butaretchi HA, Castel S, Andrade AG. Estudantes da Faculdade de Medicina da Universidade de São Paulo: uso de substancias psicoativas em 1991. Rev ABPAPAL 1995; 17(2): 47-54.

6 Bucher R. Drogas e drogadição no Brasil. Porto Alegre: Artes Médicas; 1992.

7. Queiroz S. Fatores relacionados ao uso de drogas e condições de risco entre os alunos de graduação da Universidade de São Paulo. São Paulo; 2000. [Tese de Doutorado - Faculdade de Saúde Pública da USP].

8 Carlini EA, Carlini-Cotrim B, Silva-Filho AR. Sugestões para programas de prevenção ao abuso de drogas no Brasil. São Paulo: CEBRID - Escola Paulista de Medicina; 1990.

9 Smart RG, Hughes P, Johnston LD, Anumonye A, Khant U, Mora MEM et al. A methodology for student drug-use surveys. Geneva: WHO Offset Publication; 1980.

10 Moss HB, Bonicatto S, Kirisci L, Girardelli AM, Murrelle L. Substance abuse and associated psychosocial problems among Argentina adolescents: sex, heterogeneity and familial transmission. Drug Alcohol Depend 1998; 52(3): 221-30.

11 Jackson C, Henriksen L, Dickinson D, Levine DW. Early use of alcohol and tobacco: relation to child competence and parental behavior. Am J Public Health 1997; 87: 359-64.

12 Hops H, Duncan TE, Duncan SC, Stoolmiller M. Parent substance use as a predictor of adolescent use: a six-year lagged analysis. Ann Behav Med 1996; 18(3): 157-64.
13 Swan N. Early childhood behavior and temperament predict later substance use. NIDA Notes [on line]1995; 10(1):[5 screenings]. Available from <URL: http://165.112.78.61/ NIDA_Notes/NNVOLlON1/ Earlychild html> [1998 April 9].

14 Blackson T, Tarter R. Individual, family, and peer affiliation factors predisposing to earlyage onset of alcohol and drug use. Alcohol: Clin Exp Res 1994; 18(4): 813-21.

15 Nazar-Beutelspacher A, Tapia-Conyer R, Villa Romero A, Leon Alvarez G, Medina-Mora ME, Savatierra-Izaba B. Factores asociados ai consumo de drogas en adolescentes de áreas urbanas de México. Salud Publica Mex 1994; 36: 646-54.

16 Freud S. Obras completas. Trad. Torres LLB. $3^{\text {a }}$ ed. Madrid: Biblioteca Nueva; 1972. Psicologia de las masas y analisis del yo; p. 2563-2610.

17 Aberastury A, Salas EJ. A paternidade: um enfoque ; psicanalítico. $3^{\mathrm{a}}$ ed. Porto Alegre: Artes Médicas; 1991.

18 Molina B, Chassin L, Curran P. Comparisons of mechanisms underlying substance use for early adolescent children of alcoholics and controls. J Stud Alcohol 1994; 55(3): 269-75.

19 Smith C, Lizotte AJ, Thornberry TP, Krohn MD. Resilient youth: identifying factors that prevent high-risk youth from engaging in delinquency and drug use. In: Hagan J, editor. Delinquency and disrepute in the life course. Greenwich, CT: JAI Press; 1995. p. 217-47.

20 Hawkins JD, Catalano RF, Miller JY. Risk and protective factors for alcohol and other drug problems in adolescence and early adulthood: implications for substance abuse prevention. Psychol Bull 1992; 112: 64-105.

21 D’Assumpção EA. Um perfil do uso de drogas entre estudantes universitários. Folha Med 1988; 97(5/6): 309-12.

22 Villa JAP, director. Estudio National de Salud Mental y Consumo de Substancias Psicoactivas - Colombia 1993. $2^{a}$ ed. Santafé de Bogotá: Ministerio de Salud; 1995.

23 Yamaguchi K, Kandel DB. Patterns of drug use from adolescence to young adulthood: III. Predictors of progression. Am J Public Health 1984; 74(7): 673-81.

24 Khavari KA. Interpersonal Influences in College students initial use of alcohol and drugs: the role of friends, self, parents, doctors, and dealers. Int J Addict 1993; 28(4): 377-88.

25 Duncan TE, Duncan SC, Alpert A, Hops H, Stoolmiller M, Muth NB. Latent variable modeling of longitudinal and multilevel substance use data. Multivariate Behav Res 1997; 32: 275-318. 
26 Bachman JG, Johnston LD, O’Malley PM, Humphrey RH. Explaining the recent decline on marijuana use: diferentiating the effects of perceived risks, disapproval, and general lifestyle factors. J Health Soe Behav 1988; 29: 92-112.

27 Johnston LD, O’Malley PM, Bachman JG. National Survey Results on Drug Use from the
Monitoring the Future Study, 1975-1997. V.1: Secondary school students. Rockville, MD: National Institute on Drug Abuse; 1998.

28 Prendergast ML. Substance use and abuse among college students: a review of recent literature. J Am Coll Health 1994; 43: 99113. 